\title{
LA DUCTILIDAD DEL DERECHO A LA PROTECCIÓN INTERNACIONAL (REFUGIO Y PROTECCIÓN SUBSIDIARIA) ANTE LAS CRISIS HUMANITARIAS: UN DESAFÍO PARA EUROPA Y PARA EL SISTEMA EUROPEO COMÚN DE ASILO
}

\author{
ROSARIO GARCÍA MAHAMUT \\ Catedrática de Derecho Constitucional \\ Universitat Jaume I
}

\begin{abstract}
SUMARIO
I. Los desafíos que la grave crisis humanitaria plantea a la Unión Europea en el ámbito de la protección internacional. II. Una panorámica sobre la transformación normativa del Sistema Europeo Común de Asilo (SECA) y el impacto multinivel en el sistema de garantías: un diagnóstico ante la crisis. III. El Reasentamiento de los refugiados en la UE: Significado y evolución en el marco de la construcción del SECA. IV. El Reasentamiento y la Reubicación temporal como mecanismos de emergencia para afrontar la crisis de los refugiados: Un cambio de paradigma y un desafío para la UE. V. Reflexiones conclusivas: Un sistema de asilo común en la UE que garantice el derecho a la protección internacional en situaciones de crisis
\end{abstract}

\section{LOS DESAFÍOS QUE LA GRAVE CRISIS HUMANITARIA PLANTEA A LA UNIÓN EUROPEA EN EL ÁMBITO DE LA PROTECCIÓN INTERNACIONAL}

Hemos asistido atónitos a un gran éxodo de personas que huyendo de la persecución y de la guerra de Siria, de los conflictos en Afganistán o Irak, o simplemente de la penuria económica, arribaban en cientos de miles a Europa. Niños y adultos que en manos de redes delictivas sin escrúpulos morían en el ya tristemente conocido como cementerio del Mediterráneo sin llegar a pisar suelo europeo. La terrible imagen de niños y niñas ahogados en nuestras costas. La expresión de las personas, familias completas, que tuvieron que abandonar su país de- 
jándolo todo atrás para huir de una muerte segura intentando primero llegar a Europa, cruzándola después, tratando siempre de buscar refugio en ella, ha sacudido la conciencia de todos.

Hemos visto cómo la grave emergencia humanitaria desbordaba día a día a países que, como Italia y especialmente Grecia, iban asumiendo en escalada un sobresfuerzo de sus sistemas nacionales que trataban de canalizar la llegada masiva de personas traficadas por delincuentes sin escrúpulos, muchas de ellas en clara y manifiesta necesidad de protección internacional ${ }^{1}$. La Europa de los derechos y de los valores se enfrenta a una gran encrucijada que exige inmediatas respuestas.

Basta repasar las cifras y contextualizar los hechos: En 2014, según los datos del Alto Comisionado de las Naciones Unidas para los refugiados (en adelante, ACNUR), 218000 personas refugiadas y migrantes cruzaron el Mediterráneo y al menos 3.419 perdieron la vida.

Solamente a Italia en el año 2014 llegaron más de 170.000 migrantes de forma irregular, según datos de la Agencia Europea para la Gestión de la Cooperación Operativa en las Fronteras Exteriores (en adelante, Frontex). Según la Oficina Europea de Estadística (en adelante, Eurostat), 64.625 personas solicitaron protección internacional en Italia en 2014, frente a las 26.920 que la solicitaron en 2013. En los ocho primeros meses de 2015, según Frontex, llegaron a Italia de forma irregular unos 116.000 migrantes. Según las cifras de Eurostat y de la Oficina Europea de Apoyo al Asilo (en adelante, EASO), 39.183 personas solicitaron protección internacional en Italia entre enero y julio de $2015^{2}$.

Desde 2015 hasta junio de 2016 han llegado a Grecia más de un millón de personas huyendo, en su gran mayoría, de los conflictos y de la persecución tal y como constata el ACNUR ${ }^{3}$. Más de 5.000 personas han perdido la vida en el ya tristemente conocido como cementerio del Mediterráneo.

En 2015, según datos de Frontex ${ }^{4}$, más de 870.000 migrantes llegaron a la las islas griegas del Egeo (Lesbos, Samos y Chios). Es la ruta del Mediterráneo oriental la que utilizan fundamentalmente los ciudadanos sirios, iraquíes y afga-

1 La protección internacional puede comprender el estatuto de refugiado o la protección subsidiaria. Beneficiaria de la protección internacional es una persona a la que se ha concedido el estatuto de refugiado o el estatuto de protección subsidiaria. La solicitud de protección internacional «es la petición de protección presentada a un Estado miembro por un nacional de un tercer país o un apátrida que pueda presumirse aspira a obtener el estatuto de refugiado o el estatuto de protección subsidiaria, y que no pida expresamente otra clase de protección que esté fuera del ámbito de aplicación de la presente Directiva y pueda solicitarse por separado» (art. 2 de la Directiva 2011/95/UE).

2 Son datos que se recogen en el Diario Oficial de la Unión Europea (DOUE), L 248, de 24.9.2015, p. 80 .

3 http://www.eacnur.org/sites/default/files/publicacion_fichero/boletinrefugiados_junio2016.pdf

$4 \mathrm{http}$ //frontex.europa.eu/feature-stories/profiting-from-misery-how-smugglers-bring-people-to-europe-tQtYUH 
nos, generalmente a través de mafias organizadas, para cruzar desde Turquía a las islas griegas del Egeo 5 .

Actualmente, el conflicto en Siria ha generado doce millones de personas desplazadas y refugiadas. No podemos menos que coincidir con el ACNUR en que es la mayor emergencia humanitaria a la que nos enfrentamos.

Según datos de Frontex, durante los primeros meses de 2016, una media de entre 2.000 y 3.000 personas han entrado diariamente de forma irregular en Grecia desde Turquía 6 .

En este flujo mixto de personas que constantemente están llegando a Europa hay personas que se encuentran en necesidad manifiesta de recibir protección internacional (refugio o protección subsidiaria) ${ }^{7}$.

Para hacer frente a la tragedia vivida por cientos de miles de migrantes cruzando el Mediterráneo, la Comisión propuso, a través de la Agenda Europea de Migración (mayo de 2015) ${ }^{8}$, una estrategia cuyo objeto respondía a la necesidad de dotar a la UE de los instrumentos para gestionar «mejor la migración a medio y largo plazo, en los ámbitos de migración irregular, fronteras, asilo y migración legal».

La Agenda Europea de Migración recogía una serie de medidas específicas concebidas para responder de forma inmediata a la gran tragedia humana que se vive en la cuenca del Mediterráneo. Tales medidas debían servir como modelo de reacción rápida y decidida de la UE frente a futuras crisis «con independencia de la parte de la frontera exterior común que esté sometida a presión, del este al oeste y del norte al sur»?

5 No cabe obviar que la distancia entre las costas de Turquía, desde donde operan las redes de contrabando, son de 7,5 Km en el caso de Chios y de $10 \mathrm{Km}$ en el caso de Lesbos.

6 Además de haberse intensificado el tránsito de personas refugiadas y migrantes por la ruta de los Balcanes hacia Hungría atravesando Serbia y Macedonia. En 2015, tal y como recuerda CEAR en su reciente informe de 2016, los 28 países de la UE atendieron a 1.321 .600 solicitantes de protección internacional, frente a las 626.960 solicitudes que se presentaros en 2014 (Informe 2016 de la Comisión Española de Ayuda al Refugiado (CEAR): las personas refugiadas en España y en Europa, http://www.cear.es/wp-content/ uploads/2016/06/Informe_CEAR_2016.pdf).

7 Atendiendo a la definición de la Directiva 2011/95/UE, «Refugiado»: es un nacional de un tercer país que, debido a fundados temores a ser perseguido por motivos de raza, religión, nacionalidad, opiniones políticas o pertenencia a determinado grupo social, se encuentra fuera del país de su nacionalidad y no puede o, a causa de dichos temores, no quiere acogerse a la protección de tal país, o un apátrida que, hallándose fuera del país donde antes tuviera su residencia habitual por los mismos motivos que los mencionados, no puede o, a causa de dichos temores, no quiera regresar a él, y al que no se aplica el artículo 12 de la Directiva 2011/95/UE. «Persona con derecho a protección subsidiaria»: es un nacional de un tercer país o un apátrida que no reúne los requisitos para ser refugiado, pero respecto del cual se den motivos fundados para creer que, si regresase a su país de origen o, en el caso de un apátrida, al país de su anterior residencia habitual, se enfrentaría a un riesgo real de sufrir alguno de los daños graves definidos en el artículo 15, y al que no se aplica el artículo 17, apartados 1 y 2, y que no puede o, a causa de dicho riesgo, no quiere acogerse a la protección de tal país.

8 Comunicación de la Comisión al Parlamento Europeo, al Consejo, al Comité Económico y Social Europeo y al Comité de las Regiones — «Una Agenda Europea de Migración», Bruselas, 13.5.2015, $\operatorname{COM}(2015) 240$ final.

9 Ibidem, p. 4. 
Las medidas sobre las que pivota esa respuesta rápida e inmediata contenidas en la Agenda son, amén de la más elemental y básica como lo es la de salvar vidas en el mar (rescate y salvamento), las que siguen: Poner el punto de mira en las redes delictivas de traficantes; responder a las llegadas masivas en el seno de la UE: reubicación; un enfoque común a la hora de conceder protección a las personas desplazadas que necesiten protección: reasentamiento; trabajar en asociación con los terceros países para abordar la migración desde su origen y, finalmente, utilizar los instrumentos de la UE para ayudar a los Estados miembros situados en primera línea.

En este marco y contexto se han ido adoptando medidas provisionales y de carácter excepcional —vinculantes jurídicamente- en beneficio de aquellos Estados miembros que se enfrentan a una situación de emergencia al sufrir una afluencia masiva y repentina de nacionales de terceros países generando graves problemas al sistema nacional de asilo del Estado o Estados afectados.

Ello tendrá un fuerte impacto en el desarrollo normativo y aplicación efectiva del Sistema Europeo Común de Asilo (en adelante, SECA). De hecho, en abril de 2016, la Comisión Europea puso en marcha un proceso para reformar el SECA «presentando opciones para un sistema equitativo y sostenible de distribución de los solicitantes de asilo entre los Estados miembros, una mayor armonización de los procedimientos y normas de asilo con el fin de crear condiciones equitativas en toda Europa y, de esta manera, reducir los factores de atracción fomentando medidas para disminuir los movimientos secundarios irregulares, y un refuerzo del mandato de la Oficina Europea de Apoyo al Asilo. Al mismo tiempo, la Comisión va a establecer medidas para garantizar unas vías seguras y bien gestionadas de migración legal hacia Europa».

Debo precisar que este artículo no tiene por objeto central abordar, desde una perspectiva jurídica, las herramientas normativas y de políticas públicas que para atajar la situación de la migración en su globalidad está adoptando la UE.

El objeto de nuestro estudio es analizar, por un lado, los instrumentos, mecanismos y actuaciones que desde la UE se están desplegando y, por otro, evaluar en la medida de lo posible la eficacia y eficiencia en la aplicación de las medidas por parte de los Estados miembros en una situación de emergencia humanitaria inédita en la que se ven afectadas cientos de miles de personas que llegan a nuestras costas europeas y están en necesidad de protección internacional. Afluencia masiva, emergencia humanitaria, que no solamente han colapsado y desbordado los sistemas de asilo nacionales de los países que están soportando esa fuerte presión sino que, impactando de lleno en el sistema de garantías que regula el paquete normativo del SECA, están abriendo un nuevo camino y nuevos conceptos sobre los mecanismos que deben hacer efectivo el principio de solidaridad en la distribución justa y equitativa del reparto de la carga entre los distintos Estados miembros. Programas temporales de reubicación y reasentamiento están cobrando una vida propia y llegan para quedarse en la UE. 
Sin el menor atisbo de duda, y con independencia de que Europa deba tener un enfoque integral sobre la migración, la presión migratoria que soportan aquellos países europeos con frontera exterior pone directamente en jaque el sistema nacional de asilo del país receptor y, por ende, al del resto de los Estados miembros que no cumplen con sus obligaciones nacionales, comunitarias e internacionales. Dicho de otro modo, si un derecho vale lo que vale sus garantías, el derecho de las personas en necesidad de protección internacional resulta en buena medida papel mojado ante estas situaciones a las que se está tratando de dar respuestas por parte de la UE. Muy insatisfactorias, por cierto, por parte de los Estados miembros que deben solidarizarse y asumir el reparto de la carga frente al colapso que sufren los Estados con excesiva presión.

Si bien resulta evidente que la migración debe producirse de forma regular, segura y por los causes procedimentales oportunos, no es menos cierto que cuando la migración se produce de forma irregular hay que canalizarla cumpliendo escrupulosamente con los derechos y las garantías anejas de las que gozan las personas que llegan al territorio de la Unión. El problema se halla cuando, frente a los flujos irregulares de migrantes, los Estados no actúan desde el minuto cero cumpliendo con las obligaciones derivadas del Derecho internacional y del Derecho comunitario - informando, canalizando y sustanciando con todas las garantías los procedimientos oportunos - para que las personas que están en necesidad de protección internacional (refugio y /o protección subsidiaria) gocen de su derecho a obtenerla. Frente a flujos migratorios masivos y continuados no cabe excepcionar en cualquiera de sus dimensiones, formal o sustantiva, el sistema de garantías que hace efectivo el derecho de las personas que están en necesidad de protección internacional a obtener su correspondiente reconocimiento y el primero de sus derechos asociados es el principio de no devolución.

El SECA no fue diseñado para hacer frente a situaciones de emergencia y a la presión desproporcionada sobre los sistemas nacionales de asilo. Para afrontar en el futuro de forma estable y estructural a tales desafíos la Comisión está abordando una propuesta de reforma global del SECA. El 4 de mayo de 2016 la Comisión ${ }^{10}$ en una primera fase ha propuesto modificaciones legislativas para reformar el sistema de Dublín, reforzar el sistema Dactiloscopia Europea (en adelante, EURODAC) y para transformar la Oficina Europea de Apoyo al Asilo existente en una auténtica Agencia Europea para el Asilo. A esta primera fase le seguirá una segunda fase que consistirá en presentar propuestas legislativas para reformar los procedimientos de asilo, las Directivas sobre reconocimiento del estatuto de refugiado, así como la Directiva sobre las condiciones de acogida, para garantizar la reforma completa de todas las partes del sistema de asilo de la UE. Tales pro-

10 Comunicación de la Comisión al Parlamento Europeo y al Consejo - «Hacia una reforma del Sistema Europeo Común de Asilo y una mejora de las vías legales a Europa», Bruselas, 6.4.2016, COM (2016) 197 final. 
puestas constituyen el fruto de la experiencia acumulada, especialmente la de estos dos últimos años, para afrontar una situación de emergencia, una valoración de los mecanismos —utilizado este término en sentido amplio- que se han puesto en marcha así como las deficiencias detectadas durante todo el proceso, en el que a día de hoy, aún estamos inmersos. En consecuencia, comprender en su globalidad las medidas que se han ido adoptando y las respuestas insolidarias de los Estados, cuando no directamente contrarias a derecho, ayudarán a evaluar con sosiego y perspectiva la concreción de las reformas y el contenido de las mismas.

\section{UNA PANORÁMICA SOBRE LA TRANSFORMACIÓN NORMATIVA DEL SECA Y EL IMPACTO MULTINIVEL EN EL SISTEMA DE GARANTÍAS: UN DIAGNÓSTICO ANTE LA CRISIS}

En la UE se ha pasado de la consideración del derecho de asilo como un derecho de soberanía nacional a una construcción supranacional que tiene por objetivo hacer de la UE un espacio único de protección donde este alcance las máximas cotas.

La finalidad del SECA no ha sido otro que el establecimiento de un espacio común donde se garantizarán altos niveles de protección a los refugiados y a las personas que no reuniendo los requisitos para obtener la condición de refugiados se enfrentasen, en caso de regresar a su país, a un riesgo real de sufrir daños graves (protección subsidiaria). La construcción de ese sistema europeo común de asilo es de carácter permanente. Su desarrollo normativo ha venido marcado por dos fases bien diferenciadas y sus ejes básicos descansan en la finalidad que persigue el art. 78 TFUE y en las obligaciones derivadas de los distintos instrumentos internacionales y supranacionales para la protección internacional, fundamentalmente, de la Convención de Ginebra de 1951 y el Protocolo de Nueva York de 1967 sobre el estatuto de los refugiados; el Convenio Europeo para la protección de los Derechos Humanos y de las Libertades Fundamentales que sin reconocer expresamente el derecho de asilo bajo el paraguas, esencialmente, de los arts. 3, 5, 6 y 8 ha constituido un poderosísimo instrumento para garantizar, en sentido amplio, derechos asociados a la protección internacional y la Carta de Derechos Fundamentales de la UE que expresamente en su art. 18 regula el derecho de asilo y el art. 19 hace referencia a la protección en caso de devolución, expulsión y extradición.

Dado que sobre el particular me he detenido en otro lugar y son numerosos los estudios que se han llevado a cabo, me limitaré, de forma sucinta, a recordar lo siguiente:

A diferencia de la primera fase del SECA (1999-2004), cuyo objetivo era la armonización de los marcos jurídicos de los Estados miembros a través de normas 
mínimas comunes, la segunda fase del SECA (2005-2012) ${ }^{11}$ fijó como objetivos el establecimiento de un procedimiento común de asilo y de un estatuto uniforme para aquellas personas a las que se les concedía el asilo o protección subsidiaria, la consolidación de la cooperación práctica entre las administraciones nacionales responsables en materia de asilo y un impulso de la dimensión exterior del asilo $^{12}$. Desde junio de 2014, y en atención a lo que fijó el Consejo Europeo, la transposición plena y la aplicación efectiva del SECA se ha instaurado como una prioridad absoluta.

Todo ello se ha traducido en un paquete normativo que se ha ido modificando y refundiendo y cuya evolución es permanente y de obligado cumplimiento por parte de los Estados, si bien siguen persistiendo grandes divergencias entre los Estados cuando interpretan y aplican las Directivas. Estas divergencias se evidencian muy especialmente cuando afectan a aquellas disposiciones discrecionales que contienen la Directiva de procedimientos y la Directiva sobre condiciones de acogida.

A modo de trazo grueso, hoy ese paquete normativo lo integran, básicamente, la Directiva 2011/95/UE del Parlamento Europeo y del Consejo, de 13 de diciembre de 2011, por la que se establecen normas relativas a los requisitos para el reconocimiento de nacionales de terceros países o apátridas como beneficiarios de protección internacional, a un estatuto uniforme para los refugiados o para las personas con derecho a protección subsidiaria y al contenido de la protección concedida (refundición); la Directiva 2013/32/UE del Parlamento Europeo y del Consejo, de 26 de junio de 2013, sobre procedimientos comunes para

11 A pesar de haber previsto el 2010 como fecha en la que se debía tener constituido el SECA se reprogramó la fecha para el 2012, como consecuencia del Tratado de Lisboa.

12 La Comisión en el «Plan de Política de Asilo: Un planteamiento Integrado de la Protección en toda la UE» identificó en la evolución del asilo, como ya en su momento analicé, tres tendencias principales: 1.Un descenso en el número de demandas de asilo en la mayor parte de los Estados miembros. Si bien se apreciaba que algunos de los Estados fronterizos habían experimentado un aumento en el flujo de asilo. 2. Incluso, después de haberse procedido a realizar una cierta armonización legislativa en la UE, se seguía produciendo disparidad en las decisiones de aceptación o rechazo de las demandas de asilo procedentes de solicitantes de los mismos países de origen. La falta de unas prácticas comunes, las distintas tradiciones y la diversidad de las fuentes de información en el país de origen, entre otras razones, estaban produciendo resultados divergentes. En consecuencia, se estaban creando movimientos secundarios y ello resultaba contrario al principio de proporcionar un acceso similar a la protección internacional en toda la UE. 3. Se constataba un porcentaje cada vez mayor de solicitantes a los que se les concedía una protección subsidiaria u otro tipo de estatuto de protección en virtud de la legislación nacional, en lugar del estatuto de refugiado con arreglo a la Convención de Ginebra. Ello respondía al hecho probable de que en la actualidad el aumento de conflictos y persecuciones no se contemplaban en la Convención de Ginebra. De ahí la importancia de prestar especial atención en la segunda fase del SECA a la protección subsidiaria y a otras formas de protección. [Véase la Comunicación de la Comisión al Parlamento Europeo, al Consejo, al Comité Económico y Social Europeo y al Comité de las Regiones de 17 de junio de 2008. Plan de Política de Asilo: Un planteamiento Integrado de la Protección en toda la UE (COM(2008) 360 final]. Remitimos también sobre el particular a GARCía MAHAMUT, R., «El nuevo régimen jurídico del derecho de asilo y de la protección subsidiaria en España a la luz de la Ley 12/2009, de 30 de octubre: principales novedades y desafíos», en GARCía MAHAMUT, R. y GaPALASORO, J., Régimen del Derecho de Asilo en la Ley 12/2009, CEPC, Madrid, 2010, pp. 28 y ss. 
la concesión o la retirada de la protección internacional (refundición); la Directiva 2013/33/UE del Parlamento Europeo y del Consejo, de 26 de junio de 2013 , por la que se aprueban normas para la acogida de los solicitantes de protección internacional (texto refundido); el Reglamento (UE) 604/2013 del Parlamento Europeo y del Consejo, de 26 de junio de 2013, por el que se establecen los criterios y mecanismos de determinación del Estado miembro responsable del examen de una solicitud de protección internacional presentada en uno de los Estados miembros por un nacional de un tercer país o un apátrida (texto refundido) y el Reglamento (UE) 603/2013 del Parlamento Europeo y del Consejo, de 26 de junio de 2013, relativo a la creación del sistema «Eurodac» para la comparación de las impresiones dactilares para la aplicación efectiva del Reglamento (UE) n. ${ }^{\circ}$ 604/2013.

Sin detenernos en el contenido de las Directivas y Reglamentos no podemos obviar el marco de garantías sobre el que se sustenta la evolución y la reforma de los mismos así como cuando se interpretan y aplican las mismas por parte de los Estados miembros.

Por un lado, la refundición y modificación de la Directiva sobre normas mínimas y contenido del estatuto, de la Directiva de procedimiento así como la de acogida o las reformas del Reglamento de Dublín no solamente responden a necesidades y realidades cambiantes que afectan en un sentido amplio a la protección internacional. También a la obligación de incorporar las contínuas decisiones, por un lado, del Tribunal Europeo de Derechos Humanos (en adelante, TEDH) condenando a los países por vulneración del Convenio Europeo cuando interpretan la normativa comunitaria y las aplican en su derecho interno. Por otro lado, por la interpretación que realiza el Tribunal de Justicia de la UE (en adelante, TJUE) de las Directivas del SECA en sus pronunciamientos de cuestiones prejudiciales, cuando no por la anulación directa de disposiciones de las mismas ${ }^{13}$.

Por lo que afecta al TEDH recordemos la trascendencia de su jurisprudencia en el ámbito de las cláusulas discrecionales — de las Directivas y Reglamento de Dublín-que son aplicadas por los Estados miembros y, en el caso concreto, ha delimitado la actuación de los Estados a través de una interpretación y aplicación acorde con el principio de no devolución interpretado a la luz de la prohibición de la tortura y los tratos inhumanos o degradantes.

De especial interés, por ejemplo, resulta la STEDH en el caso MSS $v$ Belgium and Greece, de 21 de Enero de 2011, condenando a Bélgica y Grecia por violación de los arts. 3 y 13 del Convenio. Esta sentencia condicionó la nueva redacción

13 El Parlamento Europeo mediante recurso solicitó, con carácter principal, la anulación de los arts. 29, apartados 1 y 2, y 36, apartado 3, de la Directiva 2005/85/CE del Consejo, de 1 de diciembre de 2005, y, con carácter subsidiario, la anulación de esta Directiva en su totalidad. El Tribunal de Justicia (Gran Sala) anuló en su Sentencia, de 6 de mayo de 2008, el art. 29, apartados 1 y 2, (relativo a la «Lista mínima común de terceros países considerados de origen seguros») y el art. 36, apartado 3, («Concepto de terceros países seguros europeos») de la Directiva 2005/85/CE del Consejo. 
dada al art. 17.1 del Reglamento de Dublín III sobre las cláusulas discrecionales relativas al Estado miembro que puede decidir examinar una solicitud de protección internacional aun cuando el examen no le incumba en virtud de los criterios establecidos en el Reglamento ${ }^{14}$.

No podemos menos que compartir la apreciación de que las sentencias del $\mathrm{TEDH}^{15}$ se han convertido en garantías de la protección internacional en la aplicación por parte de los Estados miembros de las Directivas y Reglamentos que inciden directamente en la protección internacional de los demandantes de asilo o de cualquier otra protección subsidiaria.

En el estricto ámbito comunitario el sistema de protección internacional se ha visto fortalecido por algunas decisiones que sobre cuestiones prejudiciales ha debido pronunciarse el TJUE ${ }^{16}$, lo que ha llevado también a fortalecer el acervo comunitario en materia de protección internacional, siempre mejorable.

Dicho todo lo anterior cabe afirmar que la superposición de cuestiones jurídicas y de políticas públicas que intervienen multinivel terminan impactando inexorablemente en el sistema de garantías del derecho a la protección internacional. Por ello no puede perderse de vista que las disposiciones de la legislación de la UE que en este ámbito atribuyen un margen de discrecionalidad a los Estados miembros sobre numerosos aspectos relativos a la definición de los contenidos, de los procedimientos, etc., no amparan al Estado miembro en su ordenamiento interno a legislar en modo alguno, de forma contraria a los Principios generales de la Unión, a la Carta de los Derechos Fundamentales o al Convenio Europeo de los Derechos Fundamentales.

Pero a más, por lo que afecta directamente al sistema de garantías del derecho a la protección internacional debe tenerse muy presente que, incluso, frente a interpretaciones «originalistas» del Convenio Europeo para los Derechos Humanos, como ha expresado López Guerra, el propio TEDH ha recalcado en diversas ocasiones que éstas deban entenderse «como protección de derechos también

14 Remitimos para un análisis detenido sobre estas cuestiones al trabajo de MorGADES-GiL, S., «The Discretion of States in the Dublin III System for Determining Responsibility for Examining Applications for Asylum: What Remains of the Sovereignty and Humanitarian Clauses After the Interpretations of the ECtHR and the CJEU?», International Journal of Refugee Law, Vol. 27, Núm 3, 2015, doi:10.1093/ijrl/eev034, pp. 1-24.

15 Para obtener una perspectiva detallada recomendamos la consulta del Manual de Derecho europeo sobre asilo, fronteras e inmigración, Agencia Europea de los Derechos Fundamentales y Consejo de Europa, 2014. Este Manual ha sido elaborado por Tribunal Europeo de Derechos Humanos y la Agencia de los Derechos Fundamentales de la Unión Europea (http://www.mjusticia.gob.es/cs/Satellite/Portal/es/areas-tematicas/area-internacional/tribunal-europeo-derechos/manuales-fichas-tematicas).

16 A modo de botón de muestra, resulta de especial relevancia la Sentencia del TJUE sobre las peticiones de decisión prejudicial que tenían por objeto la interpretación del art. 4 de la Directiva 2004/83/CE y de los artículos 3 y 7 de la Carta de los Derechos Fundamentales en relación a la evaluación de las solicitudes de concesión del estatuto de refugiado referido a la orientación sexual declarada de un solicitante de asilo, cuya solicitud se basaba en el temor a ser perseguido por razón de dicha orientación. [Caso A, B y C (Gran Sala) v. Staatssecretaris van Veiligheid en Justitie. Sentencia de 2 diciembre 2014 ]. 
en el contexto de circunstancias cambiantes o imprevistas respecto de la existentes en el momento de su aprobación; el Convenio sería un instrumento vivo que aspira a mantener su vigencia y efectividad a través de cambios sociales de todo tipo ${ }^{17}$. Ello es lo que explica que el propio TEDH haya alterado su jurisprudencia «en cuanto a la determinación del contenido de un derecho, teniendo en cuenta la evolución de las condiciones existentes en el contexto europeo, y el desarrollo de un consenso o standard consolidado al respecto en el ámbito de los países miembros» ${ }^{18}$.

En fin, si avanzar por la senda de una mayor armonización en la defensa de los derechos de las personas en necesidad de protección internacional en la UE que garantice altos estándares de protección ya resulta complejo en situaciones de normalidad, en situaciones de crisis las reformas que afectan al sistema en su globalidad requieren como mínimo una metodología propia que analice los impactos y sus consecuencias.

Por todo ello no puedo menos que compartir la afirmación de la Comisión de que «hacer del actual SECA un sistema más equitativo, eficiente, sostenible, basado en normas comunes y que responda a un reparto más justo de responsabilidades entre los distintos Estados miembros de la UE, constituye una exigencia elemental para garantizar el derecho a la protección internacional de las que gozan todas las personas susceptibles de recibir tal protección».

La cuestión es cómo hacerlo y que las políticas nacionales que subyacen en direcciones opuestas a sus afirmaciones mediáticas no minen esa apuesta común dentro de sus fronteras.

\section{EL REASENTAMIENTO DE LOS REFUGIADOS EN LA UE: SIGNIFICADO Y EVOLUCIÓN EN EL MARCO DE LA CONSTRUCCIÓN DEL SECA}

Uno de los instrumentos que está cobrando un papel nuclear para responder al objetivo de un reparto más justo de responsabilidades entre los distintos Estado miembros para hacer del sistema de asilo en la UE un sistema sostenible, sin duda, ese es el reasentamiento de los refugiados. En el futuro constituirá un mecanismo basilar para afrontar distintos objetivos en las políticas de migración y Asilo en la UE y en las políticas nacionales de los distintos Estados miembros, tal y como anticipé en su momento.

El salto cualitativo conceptual que se ha producido durante esta crisis con el reasentamiento de los refugiados — compensando la obligación de los Estados de

17 Lopez Guerra, L., «El sistema europeo de protección de derechos humanos», en Protección multinivel de Derechos Humanos. Manual de derecho europeo, 2013, p. 179 (https://www.upf.edu/dhes-alfa/materiales/ manual_pmdh.html).

18 Ibidem, p. 179. 
reubicar refugiados con los esfuerzos que los mismos realicen en materia de reasentamiento y su ulterior transformación- exige comprender jurídicamente el concepto y la evolución del mismo en la construcción del SECA.

A tales efectos, realizaré algunas precisiones conceptuales en torno al reasentamiento de los refugiados y sobre las que ya he profundizado en otro lugar ${ }^{19}$ :

1. El reasentamiento es un instrumento a través de cual un Estado selecciona, traslada y acoge en su país a refugiados que no pueden permanecer en un país de primer asilo por razones de seguridad (extensión transfronteriza de un conflicto al país de primera acogida, presencia de elementos del país perseguidor en el país de primera acogida, etc.) o de inexistencia de unas condiciones mínimas de subsistencia (enfermedades que no pueden ser atendidas en el país de primera acogida, crisis de refugiados de larga duración que agotan las capacidades del país de primera acogida, etc.) y les protege con un estatuto estable de residencia ${ }^{20}$.

2. Ahora bien, el reasentamiento a un tercer país, como ha subrayado AC$\mathrm{NUR}^{21}$, es una posibilidad de carácter excepcional a la que se recurre únicamente en algunos casos muy específicos que cumplen con criterios determinados. Efectivamente, el reasentamiento se considera como el último recurso para el refugiado que no puede ni regresar a su país de origen ni permanecer en el país tercero con garantías de seguridad. De ahí que, como también ha puesto de manifiesto el ACNUR, «la decisión de reasentar a un refugiado normalmente sólo se toma en ausencia de otras opciones tales como la repatriación voluntaria y la integración local, o cuando, bajo un enfoque integral de las soluciones duraderas, el reasentamiento se presenta como la solución óptima para un individuo o grupos de refugiados». Por ello el reasentamiento es una de las tres soluciones duraderas junto con la repatriación voluntaria y la integración social.

3. El reasentamiento ha constituido una clara expresión de solidaridad internacional y un eficaz mecanismo de distribución de responsabilidad entre los Estados porque, como bien ha apreciado ACNUR, ello permite compartir de manera equitativa la carga entre los Estados a la vez que reducir los problemas que afectan al país de primer asilo.

19 García Maнамut, R., «Reflexiones constitucionales sobre el reasentamiento de refugiados: El régimen jurídico del reasentamiento en Canadá y en España a la luz de la nueva ley de asilo y de la protección subsidiaria», Revista de Derecho Político, n. ${ }^{\circ} 78,2010$, pp. 43-93.

20 El estatuto proporcionado garantiza la protección contra la devolución forzada y permite que el refugiado reasentado y su familia o dependientes tengan acceso a derechos similares a aquellos que disfrutan los nacionales.

21 Resulta de especial importancia a efectos procedimentales y conceptuales la consulta del Manual de Reasentamiento del ACNUR. Edición revisada de 2011 (http://www.acnur.org/que-hace/soluciones-duraderas/ reasentamiento/manual-de-reasentamiento-del-acnur/). 
4. Los programas de reasentamiento no son sustitutivos de, ni incompatibles con, los sistemas nacionales a través de los cuales se sustancia y determina de forma individual la protección internacional. Los Estados, como no puede ser de otro modo, están obligados a atender y, en su caso, otorgar protección internacional a aquellas personas que llegan a su territorio demandando tal protección.

Realizadas las precisiones anteriores y centrándonos en la UE debe destacarse lo siguiente: En el propio origen de la construcción del SECA el reasentamiento se ha previsto y se ha concebido como una expresión de la dimensión exterior de la política de asilo de la Unión Europea, entendida ésta como un instrumento que contribuye a resolver situaciones prolongadas y difíciles o para dar respuesta a situaciones de emergencia humanitaria fuera de la UE. Las políticas de reasentamiento han constituido en la UE una manifestación voluntaria de solidaridad de los Estados nacionales frente a los refugiados y frente a los países de primera acogida.

De hecho, en septiembre de 2005, y en consonancia con lo establecido en el Programa de la Haya, la Comisión ${ }^{22}$ adoptó una Comunicación sobre los Programas Regionales de Protección cuyo objetivo era aumentar la protección de los refugiados en determinadas zonas del planeta ${ }^{23}$ en asociación con terceros países. Se subrayaba entonces que el reasentamiento debía ser un elemento central de la asistencia ofrecida a los países de primera acogida.

Recordemos que en el Libro Verde sobre el futuro Sistema Europeo Común de Asilo (junio de 2007) no solo se destacaba la importancia del reasentamiento como una parte importante de la dimensión exterior de la política de asilo de la Unión Europea sino que también incentivaba a los Estados miembros avanzar en este ámbito ${ }^{24}$.

El Plan de Acción de Asilo (junio de 2008) realizado por la Comisión a partir de las contribuciones realizadas en el Libro Verde recogía entre sus varios compromisos el de presentar un esquema de reasentamiento comunitario. El reasentamiento como un instrumento de protección eficaz para satisfacer la necesidad de protección de los refugiados en terceros países y mostrar la solidaridad con los terceros países de primer asilo debía ser objeto de un ulterior desarrollo tal y como recogía el Plan.

22 Comunicación de la Comisión al Consejo y al Parlamento Europeo sobre los programas regionales de Protección, Bruselas, 1.9.2005, COM (2005) 388 final.

23 Recordemos, por ejemplo, los Programas Regionales de Protección que se han desarrollado en Tanzania en Ucrania, Belarús o Moldova.

24 En esta línea cabe destacar que para el período 2008-2013 el Fondo Europeo para los Refugiados (FER III) previó la asistencia financiera para el reasentamiento de refugiados procedentes de terceros países en los Estados miembros de la UE (Decisión n. ${ }^{0}$ 573/2007/CE del Parlamento Europeo y del Consejo, de 23 de mayo de 2007, por la que se establece el Fondo Europeo para los Refugiados para el período 2008-2013 [...] (DO L 144 de 6.6.2007, p. 1). 
Por su parte, el Pacto Europeo sobre Migración y Asilo (octubre 2008) en el Capítulo IV rubricado («Construir una Europa del Asilo»), instaba a poner en marcha la posibilidad del reasentamiento de refugiados por parte de los Estados miembro además de la recolocación intracomunitaria en situaciones de crisis $^{25}$. Si bien, sobre una base voluntaria por parte de los Estados para reinstalar en su territorio a los refugiados.

A todo ello debe unirse la idea que latía en la propuesta de creación de la $\mathrm{EASO}^{26}$ — febrero 2009-, en la medida de que ésta no solamente debía proporcionar un marco estructural para realizar actividades prácticas en materia de cooperación en el ámbito del asilo sino también actividades relacionadas con el reasentamiento.

El reasentamiento como instrumento efectivo de esa dimensión exterior del Asilo evoluciona en un contexto en el que el uso estratégico del reasentamiento por parte de la UE se pone en valor en el marco de las políticas de migración y asilo dentro de la Unión.

Buena expresión de ello es la propuesta que realiza la Comisión, en septiembre de 2009, de creación de un «Programa conjunto de la UE en materia de reasentamiento». Este programa propone convertir el reasentamiento dentro de la UE en un instrumento más eficaz para proteger a los refugiados, consiguiendo una cooperación más estrecha y práctica entre los Estados miembros de la UE. Este programa quiere cumplir un triple objetivo: «1) incrementar el impacto de la labor humanitaria de la UE al hilo de la mejora de la orientación y el incremento del apoyo proporcionado por ella a la protección internacional de los refugiados a través del reasentamiento; 2) aumentar la utilización estratégica del reasentamiento, garantizando su adecuada integración en las políticas exterior y humanitaria de la UE; 3) racionalizar las medidas de reasentamiento de la UE en aras de la maximización de la eficiencia del suministro de las prestaciones $»^{27}$.

Uno de los aspectos más relevantes consiste en la distinción que se realiza en torno, por un lado, al reasentamiento en un Estado miembro de refugiados procedentes del exterior del territorio de la UE, por otro, del reasentamiento de refugiados en el interior de la UE. Si el primero constituye una medida humanitaria $y$, en consecuencia, una expresión de solidaridad, el segundo constituye un reparto de la carga que soportan determinados Estados frente a otros y, en consecuencia, se concibe como una expresión de solidaridad intracomunitaria.

25 Véase el Capítulo IV, «Construir una Europa del Asilo», del Pacto Europeo sobre Migración y Asilo aprobado por el Consejo Europeo en octubre de 2008.

26 El Reglamento por el que se crea la EASO entra en vigor el 19 de junio de 2010. El día 1 de febrero de 2011 la EASO estaba operativa como Oficina de la Unión Europea.

27 Comunicación de la Comisión al Consejo y al Parlamento Europeo relativa al establecimiento de un Programa conjunto de la UE en materia de reasentamiento, Bruselas, 2.9.2009, COM (2009) 447 final, p. 7. 
Debe subrayarse que el reasentamiento intracomunitario no se aborda en este Programa conjunto, sin embargo, sí que lo hace respecto del primero, esto es, el reasentamiento en un Estado miembro de refugiados procedentes del exterior del territorio de la UE.

No obstante, entre los Principios rectores del Programa conjunto de la UE en materia de reasentamiento, se sigue concibiendo la participación de los Estados miembros en las medidas de reasentamiento como algo voluntario. Si bien se complementa con otros principios tales como: el deber de ampliar el alcance de las actividades de reasentamiento en la UE, el de fomentar la participación de aquellos organismos, distintos de los gobiernos de los Estados miembros, que desempeñan un papel clave en el reasentamiento y, finalmente, el desarrollo de un planteamiento común de la UE en materia de reasentamiento que sea gradual. Sin duda, aumentar el número de Estados miembros que participan en las actividades de reasentamiento y proporcionar a las personas reasentadas cauces ordenados y seguros de acceso a la protección constituyen un objetivo prioritario de esa actuación conjunta de la UE.

Por ello el Programa consiste fundamentalmente «en un mecanismo que permitirá la fijación de prioridades anuales comunes en materia de reasentamiento y una utilización más eficaz de la asistencia financiera disponible en el marco del ejercicio de "compromisos de reasentamiento" del FER. De ahí, la propuesta, amén de reforzar la cooperación práctica, de modificar la Decisión del FER III, de modo que los Estados miembros que reasienten a individuos con arreglo a las prioridades anuales comunes de la UE reciban asistencia financiera ${ }^{28}$. Se trata, básicamente, de incentivar a los Estados para que participen en iniciativas de reasentamiento y en las prioridades que en esta materia sean acordadas a escala de la UE.

Porque no se pierda de vista que, tal y como se recoge en el Programa, «es necesario prever una estructura que propicie un planteamiento integrado entre el reasentamiento, otros elementos de las políticas de asilo de la UE y las políticas exteriores de la UE en su conjunto. Debe garantizarse, en especial, la coherencia con el Enfoque Global de la Migración de la UE» ${ }^{29}$.

Una de las principales misiones de la EASO ha sido proporcionar apoyo a los Estados miembros sometidos a presiones especiales. A lo que debe añadirse el fundamental papel que juega en la dimensión exterior del SECA. A la EASO le corresponde reforzar la capacidad de acogida y asilo en terceros países al objeto de ofrecer no sólo una mejor protección a los solicitantes de asilo sino facilitar el reasentamiento por parte de los Estados miembros de los refugiados de terceros países en la UE.

28 Resulta de interés la valoración que sobre el mismo realiza el ACNUR en el documento «Comentarios sobre la Comunicación de la Comisión Europea sobre el establecimiento de un Programa Conjunto de Reasentamiento de la Unión Europea y sobre la Propuesta de la Comisión Europea para la enmienda de Decisión n. ${ }^{\circ}$ 573/2007/EC estableciendo el Fondo Europeo para los Refugiados en el período del 2008 al $2013 »$.

29 Ibidem, p. 11. 
No puedo menos que recordar que en el Programa de Estocolmo ${ }^{30}$, el Consejo Europeo invita:

- al Consejo, al Parlamento Europeo y a la Comisión, a que fomenten la participación voluntaria de los Estados miembros en el Programa Conjunto de la Unión en materia de reasentamiento y aumenten el número total de refugiados reasentados, teniendo en cuenta la situación específica de cada Estado miembro;

- a la Comisión, a que elabore un informe anual para el Consejo y el Parlamento Europeo sobre los esfuerzos de reasentamiento realizados en la Unión, a que proceda a una valoración a medio plazo durante 2012 de los avances obtenidos, y a que evalúe el Programa Conjunto de la Unión en materia de Reasentamiento en 2014, con el objetivo de determinar las mejoras necesarias;

- también invita a la Comisión, a que explore, en dicho contexto y conforme proceda, nuevos planteamientos en relación con el acceso a los procedimientos de asilo dirigidos a los principales países de tránsito, tales como programas de protección para grupos particulares o determinados procedimientos para el estudio de solicitudes de asilo en los que puedan participar los Estados miembros con carácter voluntario.

\section{EL REASENTAMIENTO Y LA REUBICACIÓN TEMPORAL COMO MECANISMOS DE EMERGENCIA PARA AFRONTAR LA CRISIS DE LOS REFUGIADOS: UN CAMBIO DE PARADIGMA Y UN DESAFÍO PARA LA UE}

Ante la gran crisis de emergencia sufrida por Italia y Grecia no quisiera adentrarme en un análisis detenido del cambio de conceptos y de estructuras sin reiterar que desde la UE se han tomado medidas económicas ${ }^{31}$ y operativas ${ }^{32}$ para apoyar a ambos países en el marco de la política de migración y Asilo. Medidas que se han ido ampliando tras la gran crisis vivida a partir del 2015.

Si la Resolución del Parlamento Europeo de 28 de abril de 2015 ponía el énfasis en la necesidad de que, frente a las tragedias acaecidas en el Mediterráneo,

30 Diario Oficial de la Unión Europea, 4.5.2010, C 115/1.

31 En esta línea, por ejemplo, cabe destacar que Italia y Grecia han sido el segundo y tercer país, respectivamente, beneficiarios de los fondos provenientes del Programa de Solidaridad y gestión de los flujos migratorios para el período 2007-2013 (SOLID). Como también ha recordado el Consejo son los principales beneficiarios del Fondo de Asilo, Migración e Integración (FAMI) para el período 2014-2020. Ello, amén de las ayudas financieras de emergencias.

32 Por ejemplo, en abril de 2015 el Consejo decidió aprobar un importante apoyo operativo por parte de la EASO a través del despliegue de equipos de dicha Oficina en los Estados de primera línea para la tramitación conjunta de las solicitudes de protección internacional, registro y toma de impresiones dactilares. 
la respuesta de la Unión se basara en la solidaridad y el reparto equitativo de responsabilidades para apoyar a aquellos Estados miembros que recibían un mayor número de refugiados y solicitantes de protección internacional, en términos absolutos o relativos, entre las medidas que recogía la Agenda Europea de Migración presentada por la Comisión en mayo de 2015 para responder de forma inmediata a la gran tragedia humanitaria y que debían servir como modelo de reacción de la UE a futuras crisis, recordemos, figuraban la de «Responder a las llegadas masivas en el seno de la UE a través de la reubicación» y la de proporcionar «Un enfoque común a la hora de conceder protección a las personas desplazadas que necesitasen protección: reasentamiento».

El Consejo Europeo decidía, en junio de 2015, entre otras cosas, que se avanzara en paralelo en tres dimensiones esenciales: reubicación/reasentamiento, retorno/readmisión/reintegración y cooperación con países de origen y tránsito.

Centrándonos exclusivamente en la dimensión reubicación/reasentamiento — que es, por lo demás, la que impactará de forma directa en el paquete normativo del SECA- y siguiendo una correlación sintetizada de los hechos debemos recordar que:

Por lo que afecta a la reubicación, el Consejo Europeo alcanzó en junio de 2015 el acuerdo y el compromiso de reforzar la solidaridad y responsabilidad sobre la reubicación temporal y excepcional durante dos años, desde Italia y Grecia a otros Estados miembros de personas claramente necesitadas de protección internacional. Solicitó, así mismo, la rápida adopción de una Decisión del Consejo al efecto y concluyó que, con este objetivo, los Estados miembros deberían aprobar por consenso un reparto de estas personas que reflejase las situaciones específicas de los Estados miembros. La base de la distribución entre los distintos Estados se establece a través de unos mecanismos de equidad basados en el PIB, la población, la tasa de desempleo y el número de solicitantes de asilo ya aceptados y refugiados ya reasentados.

El programa temporal de reubicación de emergencia se establece, básicamente, a través de dos Decisiones del Consejo, en septiembre de 2015, en las que los Estados miembros se comprometieron a reubicar a 160.000 personas desde Italia y Grecia (y en su caso desde otros Estados miembros), desde entonces hasta septiembre de $2017^{33}$.

En este ámbito debemos recordar que en el marco de la política común de asilo existen mecanismos jurídicos dentro de la UE que permiten abordar situaciones de emergencia. Sin duda, el art. 78.3 del TFUE ofrece cobertura jurídica para que el Consejo - previa consulta al Parlamento Europeo y sobre la base de una propuesta de la Comisión Europea- pueda adoptar medidas provisionales y de carácter excepcional en beneficio de aquellos Estados miembros que se enfren-

33 Véase el informe sobre la reubicación de emergencias, de 22 de Septiembre de 2015, en http://europa.eu/rapid/press-release_MEMO-15-5698_en.htm 
tan a una situación de emergencia al sufrir una afluencia masiva y repentina de nacionales de terceros países generando graves problemas al sistema nacional de asilo del Estado o Estados afectados. Únicamente podrán activarse cuando se dé un determinado nivel de urgencia y gravedad de los problemas creados en el sistema de asilo del Estado o Estados miembros por una afluencia repentina de nacionales de terceros países.

Pues bien, sobre la base del art. 78.3 del TFUE, las medidas provisionales que en el ámbito de la protección internacional se han establecido en beneficio de Italia y Grecia, se adoptaron por el Consejo a través de dos Decisiones: la Decisión (UE) 2015/1523 34 y la Decisión (UE) 2015/160135.

La reubicación en virtud de tales Decisiones, afecta solo a los solicitantes que hubieran presentado su solicitud de protección internacional en Italia o Grecia, y respecto de las cuales dichos Estados habrían sido de otro modo responsables en aplicación de los criterios de determinación del Estado miembro responsable según lo establecido en el capítulo III del Reglamento de Dublín -(UE) n. ${ }^{\circ}$ 604/2013-.

El objetivo de tales medidas provisionales ha sido la de aliviar la fuerte presión que en materia de asilo han estado sufriendo Italia y Grecia reubicando en otros Estados de la UE a los solicitantes, que llegando de terceros países de forma irregular a los mencionados Estados en 2015, tienen una manifiesta necesidad de protección internacional. A través de la primera, se venía a disponer que 40.000 solicitantes de protección internacional de Italia y Grecia debían ser reubicados ${ }^{36}$ en otros Estados miembros. En la Decisión (UE) 2015/1601, se ampliaba a 120.000 el número de solicitantes de protección internacional que debían ser reubicados ya no solamente desde Italia y Grecia sino también desde «otros Estados miembros que afronten una situación de emergencia».

Respecto de los criterios que se aplican para decidir qué solicitantes deben ser reubicados se ha utilizado un sistema basado en el umbral de la tasa media de decisiones de concesión de protección internacional que en procedimientos de primera instancia se adoptan a escala de la UE respecto de las solicitudes de asilo y de protección internacional. Este umbral, fijado en el $75 \%$ de tasa de concesión,

34 Decisión (UE) 2015/1523 del Consejo, de 14 de septiembre de 2015, relativa al establecimiento de medidas provisionales en el ámbito de la protección internacional en beneficio de Italia y Grecia, DOUE, L 239 de 15.9 .2015 .

35 Decisión (UE) 2015/1601 del Consejo, de 22 de septiembre de 2015, por la que se establecen de medidas provisionales en el ámbito de la protección internacional en beneficio de Italia y Grecia, DOUE, L 248 de 24.9.2015.

36 El art. 2, f) de la Decisión (UE) 2015/1523 define «Estado miembro de reubicación» como Estado miembro responsable del examen de la solicitud de protección internacional de conformidad con el Reglamento (UE) 604/2013 presentada por un solicitante a raíz de su reubicación en el territorio de dicho Estado miembro. 
garantiza que la reubicación se aplica a nacionalidades ${ }^{37}$ con una tasa media de reconocimiento no menor del $75 \%$.

Los pilares esenciales sobre los que descansan estas Decisiones son las que siguen:

- Temporalidad de las medidas;

— La obligación de Italia y de Grecia de proporcionar soluciones estructurales para hacer frente a las presiones excepcionales que sufren sus sistemas de asilo y migración mediante el establecimiento de un sólido marco estratégico para responder a la situación de crisis e intensificar el proceso de reforma en curso en estos ámbitos;

- Excepción temporal de la aplicación de los arts. 13.1, 21, 22 y 29 del Reglamento 604/2013 del Parlamento Europeo y del Consejo. Lo que significa la excepción para Italia y Grecia de la obligación de examinar las solicitudes de protección internacional así como una excepción temporal a las fases del procedimiento, incluidos los plazos previstos en el mismo. También una supone una excepción al consentimiento del solicitante de protección internacional según el art. 7.2, del Reglamento (UE) 516/2014 del Parlamento Europeo y del Consejo;

- Apoyo financiero para el país de reubicación (6.000 euros a tanto alzado) por persona reubicada) y también para Italia y Grecia por persona a reubicar (500 euros a tanto alzado);

- Una serie de derechos y obligaciones de los solicitantes de protección internacional en el marco de estas Decisiones. En este sentido cabe destacar la prioridad que ocupa la reubicación de las personas vulnerables y su tramitación prioritaria. La reubicación de los menores no acompañados constituye una auténtica prioridad.

Cabe destacar que el art. 9 de ambas Decisiones del Consejo prevé que en caso de producirse una situación de emergencia caracterizada por una afluencia repentina de nacionales de terceros países a un Estado miembro, el Consejo, a propuesta de la Comisión y previa consulta al Parlamento Europeo, puede adoptar medidas provisionales en favor del Estado miembro en cuestión. Entre estas medidas figura la suspensión de la participación de dicho Estado miembro en la reubicación prevista en la Decisión así como posibles medidas compensatorias.

37 La información se basa en datos trimestrales de Eurostat actualizados y disponibles. Como se recuerda en el Primer informe sobre reubicación y reasentamiento de marzo de 2016, "Cuando se adoptaron las Decisiones sobre reubicación del Consejo, las nacionalidades elegibles eran Siria, Irak y Eritrea. En la primera actualización (tercer trimestre de 2015), pasaron a ser Bahréin, República Centroafricana, Eritrea, Irak, Siria, Suazilandia y Yemen» [Comunicación de la Comisión al Parlamento Europeo, al Consejo Europeo y al Consejo. Primer informe sobre reubicación y reasentamiento, Bruselas, 16.3.2016, COM (2016) 165 final, p. 7]. 
Fruto de ello, el Consejo acaba de aprobar la Decisión (UE) 2016/946, de 9 de junio de $2016^{38}$, en cuyo art. 2 se prevé la suspensión de las obligaciones de Suecia como Estado miembro de reubicación en virtud de las Decisiones (UE) 2015/1523 y (UE) 2015/1601 hasta el 16 de junio de 2017. Suspensión que, por Decisión del Consejo de 10 de marzo de 2016, ya se había dispensado a Austria durante un año para reubicar a 1.065 solicitantes.

El 21 de marzo de 2016 el Consejo realizaba una propuesta de modificación de la Decisión (UE) 2015/160139. Tal y como consta en la propuesta, la modificación consiste «en contabilizar los esfuerzos realizados por los Estados miembros en la admisión de ciudadanos sirios presentes en Turquía a través del reasentamiento, la admisión humanitaria u otras formas de admisión legal en el número de solicitantes de protección internacional que han de ser reubicados en su territorio en virtud de la Decisión 2015/1601 del Consejo. En lo que atañe a los 54.000 solicitantes mencionados en el artículo 4, apartado 1, letra c), de la Decisión 2015/1601 del Consejo, la presente modificación permite a los Estados miembros deducir, del número de solicitantes reubicados asignado, el número de nacionales sirios presentes en Turquía admitidos en sus territorios a través del reasentamiento, la admisión humanitaria u otras formas de admisión legal con arreglo a los programas nacionales o multilaterales distintos del programa de reasentamiento establecido con arreglo a las Conclusiones de los representantes de los Gobiernos de los Estados miembros, reunidos en el seno del Consejo el 20 de julio de 2015. Será de aplicación el artículo 10 de la Decisión (UE) 2015/1601 del Consejo, lo que significa que los Estados miembros que utilicen este mecanismo recibirán la suma de 6.500 EUR».

Dicho todo lo anterior, no conviene olvidar que la reubicación, tal y como se recogía en la Agenda para la Migración, debía ser una medida que debe prefigurar una solución duradera: «La UE necesita un sistema permanente para repartir la responsabilidad por el gran número de refugiados y solicitantes de asilo entre los Estados miembros». De hecho, se emplazaba a que la Comisión presentara, a más tardar a finales de 2015, «una propuesta legislativa con vistas a la implantación de un régimen de reubicación obligatorio y de activación automática para distribuir a las personas manifiestamente necesitadas de protección internacional dentro de la UE a raíz de una afluencia masiva» ${ }^{40}$.

38 Relativa al establecimiento de medidas provisionales en el ámbito de la protección internacional en beneficio de Suecia de conformidad con el art. 9 de la Decisión (UE) 2015/1523 y el artículo 9 de la Decisión (UE) 2015/1601, por las que se establecen medidas provisionales en el ámbito de la protección internacional en beneficio de Italia y Grecia.

39 Propuesta de Decisión del Consejo por la que se modifica la Decisión (UE) 2015/1601 del Consejo, de 22 de septiembre de 2015, por la que se establecen medidas provisionales en el ámbito de la protección internacional en beneficio de Italia y Grecia, Bruselas, 21.3.2016, COM (2016) 171 final.

40 Comunicación de la Comisión al Parlamento Europeo, al Consejo, al Comité Económico y Social Europeo y al Comité de las Regiones — «Una Agenda Europea de Migración», Bruselas, 13.5.2015, $\operatorname{COM}(2015) 240$ final, p. 5. 
A su vez, y por lo que afecta al Reasentamiento, recordemos que en la Agenda, al objeto de evitar que las personas desplazadas necesitadas de protección internacional tuvieran que recurrir a las redes delictivas de traficantes y de trata de personas, se solicitaba a la UE redoblar sus esfuerzos en materia de reasentamiento. De ahí que la Comisión presentara una Recomendación sobre un Programa de Reasentamiento (junio de 2015) ${ }^{41}$, en la que se propone un programa de reasentamiento a nivel de la UE para ofrecer 20.000 plazas durante un período de dos años, respondiendo al llamamiento del ACNUR.

Sin duda en la UE, tal y como constataba la Comisión Europea en junio de $2015^{42}$, existía un fuerte desequilibrio entre los distintos Estados miembros en materia de reasentamiento. Solo quince Estados miembros y tres Estados asociados tenían un programa de reasentamiento, tres Estados miembros y un Estado asociado habían aplicado medidas de reasentamiento con carácter ad hoc, mientras que el resto no había participado de los mismos. De hecho, en 2014 solamente 6.380 nacionales de terceros países necesitados de protección internacional fueron reasentados en la Unión Europea ${ }^{43}$.

De ahí que en el Programa europeo de reasentamiento propusiese incluir a todos los Estados miembros de forma que la distribución entre los Estados — y de los Estados asociados si decidían participar - se realizara con arreglo a una clave de distribución que debía basarse en: «a) el tamaño de la población (40\% de ponderación), b) el PIB total (40 \% de ponderación), c) el número medio de solicitudes de asilo espontáneas y el número de refugiados reasentados por millón de habitantes durante el período 2010-2014 (10 \% de ponderación), y d) la tasa de desempleo $(10 \%$ ponderación $){ }^{44}$.

El 20 de julio de 2015, los Estados miembros, junto con los Estados asociados de Dublín, acordaron reasentar a lo largo de dos años a 22.504 personas necesitadas de protección internacional procedentes de Oriente Medio, el Cuerno de África y el norte de África.

Sin embargo, los compromisos adquiridos por los Estados miembros en este programa de reasentamiento se basaban en compromisos voluntarios, a diferencia de lo que ocurría con las obligaciones impuestas con la reubicación. Como manifestaba la Comisión en marzo de 2016, a pesar de que el programa de reasentamiento constituía un hito importante en materia de reasentamiento, «no crea un marco claro de reasentamiento con normas y procedimientos comunes para los Estados participantes, sino que es en gran medida una compilación de programas

41 Recomendación n. ${ }^{\circ}$ 2015/914 de la Comisión de 8 de junio de 2015 sobre un programa europeo de reasentamiento. Bruselas, 8.6.2015 C (2015) 3560 final.

42 Recomendación n. ${ }^{\circ}$ 2015/914 de la Comisión..., op. cit., Bruselas, 8.6.2015 C, 3560 final.

43 Ibidem.

44 Ibidem. 
y procedimientos nacionales, que en algunos Estados miembros están todavía en fase preparatoria ${ }^{45}$.

Efectivamente, y a fecha de 15 de marzo de 2016, solamente 4.555 personas desplazadas necesitadas de protección internacional ${ }^{46}$ habían sido reasentadas en 11 países, según la información recibida de los Estados miembros y de los Estados asociados de Dublín.

En este ámbito en el informe se expone cuáles son los retos que debían abordarse con urgencia por cuanto conectan con las diferencias que se producen entre los Estados miembros en relación a los criterios de selección, duración de los procedimientos, capacidad de acogida, número de plazas disponibles, medios para la integración, retrasos ligados a las autorizaciones de salida en terceros países, todo ello, amén de la doble velocidad que se produce entre aquellos Estados con experiencia en el reasentamiento frente a aquellos que no lo han utilizado en su ámbito nacional.

Al tiempo, y con objeto de lograr disminuir el flujo irregular de migrantes procedentes de Turquía a la UE a la vez que tratar de dar una respuesta eficaz al reto de los refugiados, la Comisión comunica al Parlamento Europeo, al Consejo Europeo y al Consejo nuevas medidas operativas de la Cooperación UE-Turquía en el ámbito de la Migración en marzo del $2016^{47}$.

A nuestros efectos lo destacable de esta propuesta es retornar a Turquía todos los nuevos migrantes irregulares y los solicitantes de asilo que se encuentran en Grecia.

Bajo el paraguas de la Directiva de procedimientos se entiende que en determinadas circunstancias puede aplicarse un procedimiento acelerado, en virtud del cual no procede examinar el fondo de una solicitud. En tales supuestos las solicitudes de asilo podrían ser consideradas inadmisibles, en particular cuando cabe esperar que otro país pueda efectuar dicho examen o brindar una protección suficiente. Desde esta perspectiva considerar a Turquía como «tercer país seguro» ha constituido, la pata más endeble de este acuerdo de cooperación.

En contrapartida se propone el programa de reasentamiento «1 por $1 »$ que consiste básicamente en que por cada sirio retornado a Turquía desde las islas griegas, se reasentará a otro sirio procedente de Turquía en la UE.

Este acuerdo en la actualidad ya operativo ha vuelto a evidenciar las fallas del sistema.

45 Primer informe sobre reubicación y reasentamiento..., op. cit., Bruselas, 16.3.2016, COM (2016) 165 final, p. 19.

46 La mayoría de los países participantes reasentaron a ciudadanos sirios que se encontraban en Jordania, Líbano y Turquía.

47 Comunicación de la Comisión al Parlamento Europeo, al Consejo Europeo y al Consejo - «Nuevas medidas operativas de la cooperación UE - Turquía en el ámbito de la migración», Bruselas, 16.3.2016, COM (2016) 166 final. 
En fin, tras analizar buena parte del contenido de todas las acciones y algunas de las deficiencias que ha evidenciado la normativa comunitaria para afrontar la crisis, parece que la más eminente reforma es la que afecta al sistema de Dublín. En él se contienen las disposiciones que regulan los criterios y los mecanismos que determinan el Estado miembro responsable del examen de una solicitud de protección internacional. Conforme al Reglamento de Dublín si el Estado miembro en el que presentan su solicitud los solicitantes de asilo no es el Estado responsable para tramitarla, deben ser trasladados al Estado miembro responsable. Como magníficamente expresa la Comisión «el principal criterio para determinar quién es responsable del examen de las solicitudes de asilo en la UE es la entrada irregular a través del territorio de un Estado miembro. La lógica de este criterio se basaba en la premisa de que debia establecerse una vinculación entre la asignación de responsabilidades en el ámbito del asilo y el respeto por parte de los Estados miembros de sus obligaciones en materia de protección de la frontera exterior ${ }^{48}$. Este criterio resulta incompatible con el reparto de responsabilidad sostenible en relación con los solicitantes de asilo en toda la UE.

\section{REFLEXIONES CONCLUSIVAS: UN SISTEMA DE ASILO COMÚN EN LA UE QUE GARANTICE EL DERECHO A LA PROTECCIÓN INTERNACIONAL EN SITUACIONES DE CRISIS}

La construcción de un sistema europeo común de asilo, tal y como se ha ido pergeñando a través de las distintas fases y normativa - Directivas y Reglamentos-, constituye, en términos generales ${ }^{49}$ y en situación de normalidad, un avance en la defensa del derecho de los solicitantes de asilo o de protección subsidiaria en la UE cuando, por lo demás, se complementan con la acción del TEDH y el TJUE. Sin embargo, ese «espacio común de protección y solidaridad fundado en un procedimiento común de asilo y un estatuto uniforme para las personas a las que se concede protección internacional basado en normas de protección de alto nivel y unos procedimientos justos $y$ eficaces $»^{50}$ ha hecho aguas cuando las avalanchas migra-

48 Comunicación de la Comisión, Hacia una reforma del Sistema Europeo ..., op. cit., Bruselas, 6.4.2016, COM (2016) 197 final.

49 Sin embargo, ya se cuentan con estudios que analizan algunas de las fallas que producen aspectos de las Directivas que, si bien su objetivo es agilizar y garantizar un procedimiento más ágil y eficaz a la hora de conceder el estatuto de protección internacional a los demandantes de asilo o de protección subsidiaria, los procedimientos acelerados sin límites temporales pueden menoscabar el derecho de asilo y el derecho a la no devolución reconocidos en los arts. 18 y 19 de la Carta. Efectivamente, los plazos demasiado cortos pueden poner en jaque, entre otros, el derecho a los recursos procesales oportunos. A tales efectos, reulta de interés el estudio de Reneman, M., "Speedy Asylum Procedures in the EU: Striking a Fair Balance Between the Need to Process. Asylum Cases Efficiently and the Asylum Applicant's EU Right to an Effective Remedy», International Journal of Refugee Law, Vol. 25, n. ${ }^{\circ} 4,2014$, pp. 717-748. miembros.

50 Ello no implica que, efectivamente, se garantice un nivel igual de protección en todos los Estados 
torias se concentran en determinados Estados no pudiendo responder el sistema nacional a la exigencia ineludible del objetivo que persigue precisamente el SECA, esto es, «que las personas, independientemente del Estado miembro en que se presente su solicitud de protección internacional, deben recibir el mismo nivel de tratamiento en lo referente a la tramitación del procedimiento y la determinación del estatuto».

Qué duda cabe que una de las razones fundamentales sobre la que se sustenta esa aproximación en los distintos Estados miembros de las normas sobre los procedimientos para conceder y retirar la protección internacional es, precisamente, la de limitar los movimientos secundarios de los solicitantes de protección internacional entre los Estados, cuando tales movimientos se originan por las diferencias normativas entre los mismos. En definitiva, contribuir a reducir el asilo a la carta, esto es, en palabras de la Comisión, «reducir los factores de atracción de las personas a un pequeño número de Estados miembros», constituye una finalidad sobre la que pivotan, con distinta intensidad, todas las Directivas ${ }^{51}$.

Sin duda, igualar por encima y no por debajo el sistema de garantías y, por ende, el efectivo goce de un derecho fundamental es un factor que contribuye a la efectividad del derecho a la protección internacional en toda la UE, pero ello no toma en consideración otro tipo de variables que también juega cuando un solicitante de asilo va a un país y no a otro.

Tales apreciaciones pueden no resultar, desde la perspectiva de las políticas públicas de la Unión, suficientes para apostar por un sistema diferente. La cuestión es que el sistema pierde credibilidad ante situaciones de crisis humanitarias y avalanchas que afectan a determinados Estados y comienza a excepcionarse o legislarse en función de tales situaciones. Es en este punto donde se requiere una normativa europea expresa que prevea tales situaciones. Los flancos que deben abordarse deben tener plena cobertura jurídica y resultar coherentes con el sistema de protección del derecho de asilo.

Si la actual crisis de los refugiados ha puesto algo de manifiesto es precisamente que la situación actual del sistema europeo común de asilo, como enfatizaba el Comisario de Migraciones, «ya no es aceptable». Hacer del actual SECA un sistema más equitativo, eficiente, sostenible, basado en normas comunes y que responda a un reparto más justo de responsabilidades entre los distintos Estados miembros de la UE, constituye una exigencia elemental para garantizar el derecho a la protección internacional del que gozan que gozan todas las personas susceptibles de recibir tal protección, y muy especialmente en situaciones de crisis humanitarias.

La solidaridad internacional y el compromiso con la defensa de los derechos de las personas nacionales de terceros países que solicitan asilo o protección sub-

51 A estos efectos resulta muy ilustrativo el análisis de Gilbert, G., «Why Europe Does Not Have a Refugee Crisis», International Journal of Refugee Law, Vol. 27, n. ${ }^{\circ} 4$, pp. 531-535. 
sidiaria en alguno de los Estados de la UE obliga a profundizar y establecer de forma preceptiva para los Estados mecanismos efectivos de reparto de responsabilidades entre ellos cuando se produce una presión nacional sobre el sistema de asilo en alguno de los Estados miembros. No hay que olvidar, a pesar de que lo sucedido durante la crisis humanitaria ha evidenciado la insolidaridad de algunos Estados, que las políticas de la UE en el ámbito de los controles fronterizos, el asilo y la inmigración y su aplicación se rigen por los principios de solidaridad y de reparto equitativo de la responsabilidad entre los Estados miembros, tal y como mandata el art.80 TFUE, de forma que los actos que se adoptan por la Unión deben incluir medidas de obligado cumplimiento para la aplicación de este principio.

Existen mecanismos jurídicos dentro de la UE que han permitido tomar decisiones jurídicas vinculantes, aunque de carácter provisional, excepcional y temporal en beneficio de aquellos Estados miembros que se enfrentan a una situación de emergencia al sufrir una afluencia masiva y repentina de nacionales de terceros países generando graves problemas al sistema nacional de asilo del Estado o Estados afectados. Sin embargo, ello no ha resultado un obstáculo en las políticas nacionales que en materia de seguridad los Estados han podido aplicar $y$, en consecuencia, obstaculizar.

El concepto de tercer país seguro debe ser construido con otros mimbres jurídicos en Europa cuando se producen también crisis humanitarias de gran magnitud. No cabe una traslación sin más del concepto de forma tal que se convierta de forma casi automática a países cercanos de la UE, desde donde llega la presión migratoria, en tercer país seguro si no queremos convertir el derecho a la protección internacional en un concepto vacío de contenido. La incoherencia de tal actitud conlleva a graves fallas en el sistema de protección internacional.

Tal y como prevé la Directiva 2013/32/UE del Parlamento Europeo y del Consejo de 26 de junio de 2013 sobre procedimientos comunes para la concesión o la retirada de la protección internacional «La designación de un tercer país como país de origen seguro no podrá (...) establecer una garantía absoluta de seguridad para los nacionales de dicho país. Por su propia naturaleza, la evaluación que sustenta la designación sólo puede tener en cuenta las circunstancias civiles, jurídicas y políticas generales de dicho país y el hecho de si los agentes de la persecución, la tortura, el trato inhumano o degradante o los castigos están sometidos a sanción en la práctica cuando se los considera responsables en dicho país. Por dicho motivo, es importante que, cuando un solicitante demuestre que existen motivos válidos para que no se considere a un país como seguro en sus circunstancias particulares, la designación del país como seguro ya no puede considerarse en cuanto a lo que dicho solicitante se refiere».

La presión insostenible en los sistemas de asilo nacional especialmente de Grecia e Italia, generado por la grave crisis humanitaria y la tragedia vivida por cientos de miles de personas muchas de ellas en necesidad manifiesta de protec- 
ción internacional, no ha conseguido mitigarse a través de los mecanismos de emergencia que la UE ha habilitado para hacerles frente.

La reubicación en otros Estados de la UE y el compromiso de reasentamiento no han dado los frutos necesarios para la salvaguarda del sistema de protección internacional de forma eficiente y ágil.

Por lo que afecta a las medidas de reubicación cabe concluir que los Estados miembros no han respondido con rapidez a la ejecución de las mismas y estimamos acertado replantear para el futuro todo el sistema. Ante el aumento imparable e insostenible del flujo migratorio de Turquía a Grecia unido a la falta de respuesta eficaz por parte de los Estados miembros ha traído como consecuencia, por ejemplo, restricciones en la frontera entre Grecia y la Antigua República Yugoslava de Macedonia lo que ha aumentado la presión sobre Grecia. Esta situación, tal y como puso de manifiesto el Consejo el pasado mes de marzo ${ }^{52}$, incrementa el riesgo de que se desarrollen nuevas rutas migratorias a través de otros Estados miembros. No evita, en consecuencia, el tan temido movimiento secundario de las personas en necesidad de protección internacional. De hecho Suecia, el pasado diciembre, solicitó la suspensión de las obligaciones que derivaban de las dos Decisiones del Consejo por afrontar una situación de emergencia por la afluencia repentina de nacionales de terceros países en su territorio por «un cambio brusco en los flujos migratorios» lo que acarreó un aumento considerable del número de solicitantes de protección internacional en Suecia de personas que habían entrado en la Unión a través de Italia y Grecia. Efectivamente, «En 2015, Suecia registró con gran diferencia el mayor número de solicitantes de protección internacional respecto del número de habitantes en la Unión, con 11.503 solicitantes por millón de habitantes ${ }^{53}$.

Sin duda, y a pesar de que la actuación de la UE ante la crisis pueda tildarse de tardía y deficiente en varios aspectos, no podemos negar que se ha realizado un avance en ofrecer soluciones eficaces, en términos generales ${ }^{54}$, que habrían resultado fructíferas si los Estados miembros hubiesen actuado con diligencia y rapidez respondiendo a los cupos de reubicación en los plazos fijados en las distintas Decisiones con vinculación jurídica. También, si los Estados hubieran respondido a los objetivos de los cupos de reasentamiento cubriendo sus plazas según los programas previstos, la situación a efectos de garantizar el derecho a la protección internacional hubiera sido bien distinta. No se ha producido en un gran número

52 Propuesta de Decisión del Consejo por la que se modifica la Decisión (UE) 2015/1601 ..., op. cit., $\operatorname{COM}(2016) 171$ final.

53 Decisión (UE) 2016/946, de 9 de junio de 2016, relativa al establecimiento de medidas provisionales en el ámbito de la protección internacional en beneficio de Suecia de conformidad con el artículo 9 de la Decisión (UE) 2015/1523 y el artículo 9 de la Decisión (UE) 2015/1601, por las que se establecen medidas provisionales en el ámbito de la protección internacional en beneficio de Italia y Grecia.

54 No constituye un paso adelante el acuerdo de cooperación con Turquía en el ámbito del retorno y en la consideración de tercer país seguro. 
de Estados una traslación de las decisiones que los propios Estados miembros han adoptado en el seno de la UE a sus políticas nacionales — como administración nacional- para hacerlas efectivas y eficaces. Como ha puesto de manifiesto el Primer informe sobre reubicación y reasentamiento $0^{55}$ el número total de compromisos formales de reubicación que han realizado los Estados a 15 de marzo de 2016 es de 3.723 personas, lo que representa el 2,33\% de las 160.000 reubicaciones que deben realizarse. No podemos trasladar la responsabilidad del fracaso a la Unión como ente independiente porque la información constante sobre el seguimiento de la situación, la evaluación de los problemas y las deficiencias derivadas de la aplicación de las propias Decisiones así como las actuación de los Estados miembros han estado como información al alcance de todos los Estados miembros $^{56}$. Agilizar las propias estructuras administrativas nacionales para la consecución de los objetivos de protección internacional constituye un deber inaplazable de los Estados. Como lo es el de la UE no dar un paso hacia atrás en materia de garantías de los derechos con el argumento de poder dar varios hacia adelante.

En esta línea cobra una especial relevancia, por su gravedad, la consideración de Turquía como tercer país seguro a efectos de devolución o el esfuerzo, en ocasiones, desproporcionado que se les exige a los países que están sufriendo una enorme presión a dar cuenta de las rutas a seguir por ellos mismos en materia de devolución y retorno de los migrantes irregulares.

No podemos compartir la idea de que la reubicación como mecanismo de reparto equilibrado de la carga que sostienen algunos de los Estados miembros deba ser voluntaria para el resto de los Estados de la UE bajo el archiconocido argumento del «efecto llamada» a la migración irregular. Desde esta perspectiva la UE ha conseguido imponer cuotas y sanciones a los Estados pero la ejecución de las mismas se ha visto obstaculizada por la vía de los hechos ${ }^{57}$. Se debe avanzar en un programa estable y estructural ad hoc (paquete normativo expreso) para afrontar la presión desproporcionada de solicitantes de asilo en los sistemas nacionales. Éste puede ser trabajado desde las bases contenidas en las Decisiones del Consejo en beneficio de Italia y Grecia.

55 Comunicación de la Comisión al Parlamento Europeo, al Consejo Europeo y al Consejo. Primer informe sobre reubicación y reasentamiento, Bruselas, 16.3.2016 COM (2016) 165 final.

56 Un botón de muestra lo constituyen las distintas Comunicaciones de la Comisión sobre Gestión de la crisis de los refugiados en relación con las medidas operativas, presupuestarias y jurídicas inmediatas o sobre el estado de ejecución de las acciones prioritarias en el marco de la Agenda Europea de Migración. En esta línea, véase, COM (2015) 490, de 23 de septiembre de 2015); COM (2015) 510, de 14 de octubre de 2015; COM (2016) 85, de 10 de febrero de 2016. De hecho, la Comisión ha enviado escritos a los Estados miembros de reubicación instándoles a acelerar la aplicación de las Decisiones del Consejo y a abordar muchos de los obstáculos que ha ido identificando.

57 Solamente 937 solicitantes de asilo se han reubicado desde Grecia e Italia a fecha de 15 de marzo de 2016. Sin duda, el ritmo de traslados es absolutamente insatisfactorio, tal y como ha puesto de relieve la Comisión Europea el 16 de marzo de 2016. 
Las políticas de reasentamiento han constituido hasta hace bien poco en la UE una manifestación voluntaria de solidaridad de los Estados frente a los refugiados y frente a los países de primera acogida. La enorme presión sufrida por los sistemas nacionales de asilo de Italia y muy especialmente de Grecia ha condicionado que el reasentamiento evolucione conceptualmente como mecanismo de solidaridad no solo ad extra sino ad intra en la UE. Replantear su papel como mecanismo que debe hacer del SECA un sistema equilibrado, justo y sostenible —en la medida que también permitiría repartir la carga entre los Estadosconstituye una exigencia.

Este replanteamiento debe descansar en un doble pilar. Por un lado, se debería trabajar en la obligación jurídica de imponer cuotas de reasentamiento a los Estados miembros en situaciones de emergencia que afronte la UE. Por otro lado, los Estados deben poder desde una perspectiva nacional seguir decidiendo de forma voluntaria y discrecional programas de reasentamiento en su territorio.

Cuando el reasentamiento constituye una decisión voluntaria, exclusiva y discrecional de los Estados miembros, éstos valoran, entre otras consideraciones, el volumen de refugiados que pueden ser reasentados en su territorio, el perfil de los mismos, su capacidad de integración en sus respectivas sociedades, etc. Por ello, conviene profundizar en el reasentamiento dentro de la UE, que incorporando el margen de decisión nacional de los Estados miembros, éstas se concilien a través de procedimientos concretos y ad hoc basados en las Directivas actuales.

Lo que ha puesto de manifiesto encarnizadamente la grave crisis y la tragedia humana vivida en la cuenca del Mediterráneo es que ningún Estado miembro puede resolver el problema en sus distintas caras poliédricas por sí solo ante avalanchas humanas desesperadas que arriesgan sus vidas en el mar para arribar a Europa, aunque sea por distintos motivos al de la huida por persecución. Grecia, Italia, España, ni ningún otro país con frontera exterior puede afrontar por sí mismo una crisis de tal magnitud: Ni para rescatar y salvar las vidas en el mar, ni para dar protección internacional a las personas que huyen de persecuciones y guerras, ni para abordar los fenómenos migratorios, ni para atajar y cooperar con terceros Estados, ni para nada de nada. El difícil equilibrio de proteger nuestras fronteras, garantizar unos flujos migratorios ordenados, el cumplimiento escrupuloso del respeto de los derechos humanos y la salvaguarda de nuestros valores humanos solo se puede garantizar con una política común europea clara y coherente. Eso significa creérselo y que los Estados miembros cumplan con sus obligaciones, obligaciones justas y equitativas en el reparto de la carga.

$* * *$

TITLE: The ductility of the right to international protection (refugee status and subsidiary protection) facing with the humanitarian crises: a challenge for Europe and the Common European Asylum System

ABSTRACT: The unsustainable pressure concerning the national asylum systems, especially in Greece and Italy, generated by the severe humanitarian crisis and the tragedy undergone by bundreds of thousands 
of persons, many of them in clear need for international protection, has not managed to be mitigated throughout the emergency mechanisms taken to address them by the EU. This situation arouses serious flaws in the system of international protection and structural deficiencies in the regulatory package of the current CEAS. New principles have been developed, the need to reform the CEAS forms part and parcel of the current EU agenda. This research approaches not only a detailed analysis regarding to the mechanisms implemented by the $E U$ to cope with the critical situation but also the impact on a future CEAS reform.

RESUMEN: La presión insostenible en los sistemas nacionales de asilo especialmente de Grecia e Italia, generado por la grave crisis humanitaria y la tragedia vivida por cientos de miles de personas muchas de ellas en necesidad manifiesta de protección internacional, no ha conseguido mitigarse a través de los mecanismos de emergencia que la UE ha habilitado para hacerles frente. Esta situación ha evidenciado graves fallas en el sistema de protección internacional y deficiencias estructurales en el paquete normativo del actual SECA. Nuevos principios se han impuesto y la necesidad de reformar el SECA ya forma parte de la agenda europea. Este trabajo aborda un análisis detallado de los mecanismos habilitados por la UE para afrontar la crítica situación así como su impacto en una futura reforma del SECA.

KEY WORDS: Common European Asylum System (CEAS), international protection, asylum, refugee status, subsidiary protection status, Geneva Convention of 28 July 1951, refugee resettlement, relocation, bumanitarian crisis, Dublin system, migratory flows, migration and asylum policy, provisional measures in the area of international protection.

Palabras Clave: SECA, protección internacional, refugiados, protección subsidiaria, Convención de Ginebra de 28 de julio de 1951, reasentamiento de refugiados, reubicación, crisis humanitaria, sistema de Dublin, flujos migratorios, política de migración y asilo, medidas provisionales en el ámbito de la protección internacional.

FECHA DE RECEPCIÓN: 15.06.2016

FECHA DE ACEPTACIÓN: 27.07.2016 